\title{
The effect of current mode and discharge type on the corrosion resistance of plasma electrolytic oxidation (PEO) coated magnesium alloy AJ62
}

\author{
R.O. Hussein ${ }^{\text {a }}$, P. Zhang ${ }^{\mathrm{a}}$, X. Nie ${ }^{\mathrm{a}, *}$, Y. Xia ${ }^{\mathrm{a}, \mathrm{b}}$, D.O. Northwood ${ }^{\mathrm{a}, *}$ \\ a Department of Mechanical, Automotive and Materials Engineering, University of Windsor, Windsor, ON, Canada N9B 3P4 \\ b Institutes of Mechanics, Chinese Academy of Sciences, Beijing 100190, China
}

\section{A R T I C L E I N F O}

Article history:

Received 28 February 2011

Accepted in revised form 30 August 2011

Available online 10 September 2011

\section{Keywords:}

Magnesium

Corrosion

Plasma electrolyte oxidation

OES

\begin{abstract}
A B S T R A C T
Magnesium alloys are increasingly being used as lightweight materials in the automotive, defense, electronics, biomaterial and aerospace industries. However, their inherently poor corrosion and wear resistance have, so far, limited their application. Plasma electrolytic oxidation (PEO) in an environmentally friendly aluminates electrolyte has been used to produce oxide coatings with thicknesses of $~ 80 \mu \mathrm{m}$ on an AJ62 magnesium alloy. Optical emission spectroscopy (OES) in the visible and near ultraviolet (NUV) band ( $285 \mathrm{~nm}-800 \mathrm{~nm}$ ) was employed to characterize the PEO plasma. Scanning electron microscopy (SEM) and X-ray diffraction (XRD) were used to characterize the coated materials, and potentiodynamic polarization and electrochemical impedance spectroscopy (EIS) in a $3.5 \% \mathrm{NaCl}$ solution were used to determine the corrosion behavior. It was found that the plasma discharge behavior significantly influenced the microstructure and the morphology of the oxide coatings and, hence the corrosion resistance. The corrosion resistance of the coated alloy was increased by changing the current mode from unipolar to bipolar, where the strong plasma discharges had been reduced or eliminated.
\end{abstract}

(C) 2011 Elsevier B.V. All rights reserved.

\section{Introduction}

Magnesium's combination of high strength-to-weight ratio and lightness is especially useful in automobile components where it can reduce vehicle weight, thereby improving fuel economy and, hence, environmental friendliness [1-3]. Auto makers are motivated to increase the use of magnesium (Mg) to exceed $100 \mathrm{~kg}$ per vehicle by 2020 from the current level [4]. However, magnesium alloys exhibit very poor corrosion resistance caused by their chemically active nature, especially galvanic corrosion [5], which can further cause severe pitting corrosion on the metal surface resulting in decreased mechanical stability and an unattractive appearance. The protective properties of passive films on $\mathrm{Mg}$ are inferior to those on $\mathrm{Al}$ and $\mathrm{Ti}$, and hence magnesium alloys usually need an appropriate surface treatment.

The characteristics of currently available technologies for the corrosion protection of magnesium alloys are discussed in Refs. [6-9]. Plasma Electrolyte Oxidation (PEO) is considered as one of the most cost-effective and environmentally friendly ways to improve the corrosion and wear resistance of magnesium and magnesium alloys [10-13]. The PEO method can be used to form a thick, hard and adherent ceramic coating on the surface of Mg alloys as well as the valve metals ( $\mathrm{Al}$ and $\mathrm{Ti}$ ) and their alloys [14]. Coating surface morphology, structure and corrosion resistance are affected by many parameters including electrolyte composition [15-18], substrate material [19], and the electrical parameters, mainly current

\footnotetext{
* Corresponding authors.

E-mail addresses: xnie@uwindsor.ca (X. Nie), dnorthwo@uwindsor.ca (D.O. Northwood)
}

mode and current density [9,20]. Different current modes have been utilized in the PEO treatment including, DC, AC, unipolar and bipolar current modes [21-23]. Compared to a unipolar current operating mode, the application of bipolar current pulse regimes usually produces a denser PEO coating on Al- and Mg-alloys [24-26]. The properties of the plasma discharges themselves in the bipolar current mode differ from those of the discharges for the unipolar current mode. From the plasma discharge point of view, significant reduction of strong discharges [24] by controlling the electrical parameters during the process can reduce the detrimental effects associated with such discharge events.

Optical emission spectroscopy (OES) has previously been applied to the PEO process for the detection and analyses of light that is emitted from the plasma species for $\mathrm{Al} \mathrm{[24]} \mathrm{and} \mathrm{Mg}$ [23]. The optical emission spectra were recorded and plasma temperature profile versus processing time was constructed [24]. In these previous studies, the collective behavior of the plasma discharge over the entire surface, rather than the individual discharges, was reported. Based on the OES results, and with an assumption of local thermodynamic equilibrium (LTE) [27], plasma electron temperatures for an Al 1100 alloy have been calculated using the relative intensities of spectral lines of the same atomic or ionic species [24,25]. Evaluations based on the spectroscopic method for an $\mathrm{Al} 1100$ alloy show the electron temperatures to be in the range of $4000-7000 \mathrm{~K}$ for the unipolar current mode and 4000-5500 $\mathrm{K}$ for the bipolar current mode [20].

Mg alloy AJ62 has recently been developed as a structural automotive powertrain material. This alloy is characterized not only by a high strength-to-weight ratio synonymous with magnesium alloys but also by relatively good properties at elevated temperatures [28]. AJ62 is the 
only $\mathrm{Mg}-\mathrm{Al}$ alloy thus far to have been used in the mass production of an automotive power train crankcase [29]. The PEO process has been investigated as a way of improving the wear and corrosion resistance of this $\mathrm{Mg}$ alloy [30-31]. An attempt in this paper was made to understand the effect of current modes on the plasma discharge behavior and plasma temperature which were believed to have a significant effect on morphology and microstructures of the resultant oxide coatings for the Mg alloy. Thus, in this work, the PEO process operated at two different current modes (i.e., unipolar and bipolar pulsed DC current modes) with different electrical charge ratio $C_{R}$ to produce oxide coatings on an AJ62 magnesium alloy substrate. The application of both current modes, and the effect on coating morphology, structure and corrosion protection properties are discussed with respect to the plasma discharge behavior and plasma temperature profiles.

\section{Experimental procedures}

\subsection{Materials and PEO processing methods}

AJ62 Magnesium alloy (MgAl6Mn0.3Sr2) disk coupons $(25 \times 7 \mathrm{~mm})$ were used as the test samples in this study. They were prepared from the same cast ingot in order to minimize the differences resulting from variations in composition and microstructure. The coupons were manually ground and polished up to 1200 grit silicon carbide $(\mathrm{SiC})$ abrasive papers. After cleaning with acetone to ensure a similar initial surface condition for each sample, they were dried in cool air. The coating was obtained in an alkaline electrolyte containing sodium aluminate $\left(10 \mathrm{~g} / \mathrm{l} \mathrm{Na}_{2} \mathrm{Al}_{2} \mathrm{O}_{4}\right)$ and potassium hydroxide $(\sim 1 \mathrm{~g} / \mathrm{K} \mathrm{KOH})$ added to balance the $\mathrm{pH}$ at 12 . The temperature of the electrolytes was kept below $25^{\circ} \mathrm{C}$ by a water cooling system.

The PEO coating system used to produce the oxide coatings is similar to that used for electroplating or anodizing. It consists basically of a container with the alkaline electrolyte and a powerful electrical source (output $300-1000 \mathrm{~V}$ ). A stainless steel plate in the bath acts as a counter-electrode (cathode) with the coupons as the anode. The electrodes are connected to two pulsed DC power supplies operating under a constant current control function (after the initial transitory regime) to generate different current waveforms. During the coating process, the voltage was increased gradually with process time so as to maintain a preset current density as the coating thickness increased. The OES arrangement used in this experiment is similar to that described in Ref. [24]. To examine the effects of current mode on the resultant properties of the coatings, the PEO coating process was carried out using two different current modes:

- A unipolar pulsed-DC mode (UPDC) i.e. under only positive polarization of the metal electrode, operating at a $2 \mathrm{kHz}$ and duration time of $80 \%$ duty cycle. The specific frequency was chosen based on the dependence of coating growth rate and coating characteristics to current frequency [25].

- A bipolar current mode, comprising two components, i.e., a positive component and a negative component. Process parameters, such as the frequency ( $f=1 / T$, where $T$ is the pulse period), the duration of each pulse $\left(T_{o n}^{+}\right.$and $T_{o n}^{-}$, the period of positive and negative pulse respectively) and the resting gap (break) between the positive and negative pulses ( $T_{\text {off }}^{+}$and $T_{\text {off }}^{-}$respectively) are listed in Table 1. In each pulse, the pulsed current reached its maximum, after which it remains constant for $T_{0 n}$ time. In this work, it is represented by $T_{\text {on }}^{+}$, whereas, $T_{\text {off }}$ corresponded to $T_{\text {off }}^{+}+T_{\text {on }}^{-}+T_{\text {off }}^{-}$.

The charge ratio parameter, $C_{R}$, is introduced to represent the ratio of positive to the negative charge quantity [20]:

$C_{R}=\frac{q_{+}}{q_{-}}=\frac{\int_{0}^{T_{o n}} \mathrm{I}^{+} d t}{\int_{T_{o n}}^{T_{o n}+T_{o f f}} \mathrm{I}^{-} d t}$
Table 1

PEO process parameters for coating depositions on $\mathrm{Mg}$.

\begin{tabular}{llllllllll}
\hline Sample & Current mode & $\begin{array}{l}\text { Time } \\
(\mathrm{min})\end{array}$ & $\begin{array}{l}\mathrm{I}^{+} \\
(\mathrm{A})\end{array}$ & $\begin{array}{l}\mathrm{I}^{-} \\
(\mathrm{A})\end{array}$ & $\begin{array}{l}T_{\text {on }}^{+} \\
(\mu \mathrm{s})\end{array}$ & $\begin{array}{l}T_{\text {off }}^{+} \\
(\mu \mathrm{s})\end{array}$ & $\begin{array}{l}T_{\text {on }}^{-} \\
(\mu \mathrm{s})\end{array}$ & $\begin{array}{l}T_{\text {off }}^{-} \\
(\mu \mathrm{s})\end{array}$ & $\mathrm{C}_{\mathrm{R}}$ \\
\hline S1 & Unipolar & 45 & 1.0 & & 400 & 100 & & & \\
S2 & Bipolar & 45 & 1.0 & 0.9 & 400 & 100 & 400 & 100 & 0.74 \\
S3 & Bipolar & 45 & 1.0 & 0.7 & 400 & 200 & 600 & 100 & 0.63 \\
S4 & Bipolar & 45 & 1.0 & 0.5 & 400 & 100 & 600 & 100 & 1.0 \\
\hline
\end{tabular}

where $\mathrm{I}^{+}$and $\mathrm{I}^{-}$represent the values of the positive and negative currents respectively. Both pulse duration and current density were controlled in order to provide appropriate conditions to attain desirable coating morphology and microstructure.

\subsection{Characterization of PEO coatings}

Scanning electron microscopy (JEOL 2100 operating at $15 \mathrm{kV}$ and FEI Quanta 200 FEG with solid state backscattered detector operated at $10 \mathrm{kV}$ ) in both the secondary electron and back-scattered electron (BSE) modes was used to observe both the coating surface morphology and coating thickness and integrity through observation of sample cross sections. The samples were first sputtered with a gold film to make conductive before SEM analysis. The phases in the coatings on the Mg were studied by X-ray Diffraction (XRD) analysis using a Siemens D5000 X-ray powder diffractometer with $\mathrm{Cu} K \alpha$ radiation.

To determine the corrosion resistance of the PEO coating, potentiodynamic polarization in a $3.5 \% \mathrm{NaCl}$ solution tests were carried out for uncoated and coated samples at $25{ }^{\circ} \mathrm{C}$ using a Bio-Logic SP150 potentiostat/galvanostat with EC-Lab ${ }^{\circledR}$ corrosion software: version 10.02. A three electrode cell with the samples as the working electrode, an $\mathrm{Ag} / \mathrm{AgCl} / \mathrm{sat} \mathrm{KCl}$ reference electrode, and platinum as a counter electrode, was used in the experiments. After a 20 minute period to stabilize the open-circuit potential (OCP), potentiodynamic polarization tests were conducted from $-0.15 \mathrm{~V}$ versus open circuit potential, up to $-1.25 \mathrm{~V}$ versus the reference electrode at a rate of $1.0 \mathrm{mV} / \mathrm{s}$. Electrochemical impedance spectroscopy (EIS) equipment was also employed to determine the corrosion resistance. A aqueous $\mathrm{NaCl}$ solution at a $\mathrm{pH}$ of 6.5 was used as the test solution. The equipment was operated in the frequency range between $100 \mathrm{mHz}$ and $200 \mathrm{kHz}$ with an amplitude of $\pm 10 \mathrm{mV}$ at the corrosion potential. All EIS data were analyzed using EC-Lab® software.

\subsection{Optical emission spectroscopy}

The main characterization of the micro-discharges was performed by means of optical emission spectroscopy (OES). Light emission of the discharges was collected using one spectrometer; this spectrometer has 4 channel slots, each of which covers a certain wavelength region. The light emitted by the plasma in the wavelength range of 200-900 nm, was transmitted and focused through a quartz window and lenses [24]. Since the discharges occur randomly, an integrated signal was used which was collected from the total sample surface facing the fiber optic. The emission intensity of the plasma species were monitored as a function of time using the OES system. Six different spectral lines were recorded simultaneously, which eliminates discrepancies that may otherwise happen if the spectra are recorded at different times or with different samples [24]. Spectroscopy with the OES spectrometer was utilized to examine the spectral lines (Table 2) [27] at $285.2 \mathrm{~nm}$ (Mg I), $383.8 \mathrm{~nm}$ (Mg I), $518.3 \mathrm{~nm} \mathrm{(Mg}$ I), $486.1 \mathrm{~nm}\left(\mathrm{H}_{\beta}\right), 589.5 \mathrm{~nm}$ (Na I), and $777 \mathrm{~nm}(\mathrm{OI})$. Atomic and ionic spectral lines were identified using the NIST online spectral database [32].

The plasma studied here falls into the category of an optically thin plasma [27]. The relative intensities of spectral lines of the same atomic species can be used to calculate the plasma electron 
Table 2

Spectral lines observed in this experiment with the wavelength $(\lambda)$, transition, statistical weight of the upper and lower state $g_{k}$ and $g_{i}$ (respectively), energy difference and the transition probabilities $\left(A_{\mathrm{ki}}\right)[25]$.

\begin{tabular}{lllllll}
\hline Line & $\begin{array}{l}\lambda \\
\mathrm{nm}\end{array}$ & Transition & $\mathrm{g}_{\mathrm{k}}$ & $\mathrm{g}_{\mathrm{i}}$ & $\begin{array}{l}\text { Energy } \\
\mathrm{eV}\end{array}$ & $\begin{array}{l}\mathrm{A}_{\mathrm{ki}} \\
10^{8} \mathrm{~S}^{-1}\end{array}$ \\
\hline $\mathrm{Mg} \mathrm{I}$ & 285.2 & $3 \mathrm{~s} 3 \mathrm{p}{ }^{1} \mathrm{P} \rightarrow 3 \mathrm{~s}^{2}{ }^{1} \mathrm{~S}$ & 3 & 1 & 4.34 & 5.00 \\
$\mathrm{Mg} \mathrm{I}$ & 383.8 & $3 \mathrm{~s} 3 \mathrm{~d}^{3} \mathrm{D} \rightarrow 3 \mathrm{~s} 3 \mathrm{p}^{3} \mathrm{P}$ & 7 & 5 & 3.22 & 1.68 \\
$\mathrm{Mg} \mathrm{I}$ & 518.3 & $3 \mathrm{~s} 4 \mathrm{~s}^{3} \mathrm{~S} \rightarrow 3 \mathrm{~s} 3 \mathrm{p}^{3} \mathrm{P}$ & 3 & 5 & 2.38 & 0.57 \\
$\mathrm{H}_{\beta}$ & 486.1 & $4 \mathrm{~d}^{2} \mathrm{D} \rightarrow 2 \mathrm{p}^{2} \mathrm{P}$ & 4 & 2 & 2.55 & 0.172 \\
$\mathrm{Na} \mathrm{I}$ & 589.5 & $3 \mathrm{p}^{2} \mathrm{P} \rightarrow 3 \mathrm{~s}^{2} \mathrm{~S}$ & 3 & 3 & 1.36 & 0.614 \\
$\mathrm{O} \mathrm{I}$ & 777.2 & $2 \mathrm{~s}^{2} 2 \mathrm{p}^{3} 3 \mathrm{p}^{5} \mathrm{P} \rightarrow 2 \mathrm{~s}^{2} 2 \mathrm{p}^{3} 3 \mathrm{~s}^{5} \mathrm{~S}$ & 3 & 5 & 1.59 & 0.369 \\
\hline
\end{tabular}

temperature. Once relative intensities are known, the temperature corresponding to a given line ratio is [27]:

$\mathrm{kT}=\frac{E_{m(2)}-E_{m(1)}}{\ln \left(\frac{I(1) A_{m n}(2) g_{m}(2) \lambda_{0}(1)}{I(2) A_{m n}(1) g_{m}(1) \lambda_{0}(2)}\right)}$

where $\mathrm{kT}$ is the thermal energy, $I(1)$ and $I(2)$ relative line intensities of lines of the same species in question, $A_{m n}(i)$ the transition probabilities, $m$ the upper and $n$ the lower level of the respective lines, $g_{m}(i)$ the statistical weight of the upper levels, $E_{m}(i)$ energies of the upper levels of lines and $\lambda_{0}$ (i) the wavelengths of the line centers in vacuum. Eq. (2) is valid if the level populations of the lines in question are populated according to the Boltzmann law: in other words, at least partial thermodynamic equilibrium (LTE) must exist for these levels.

The spectral lines selected for the calculation should belong to the same atomic or ionic species and are emitted in the same ionization stage. In this case, the emission intensities of the selected Mg spectral lines were simultaneously recorded, and the intensity ratio of $518.3 \mathrm{~nm}(\mathrm{Mg} \mathrm{I})$ to $383.8 \mathrm{~nm}$ (Mg I) (from the same ionization stage) was used to calculate the plasma electron temperature $\left(T_{e}\right)$ based on the partial thermodynamic equilibrium model (LTE). Since it has negligible effects, the line broadening effect was ignored in this experiment. More detailed information on the calculation method can be found in Ref. [24].

\section{Results and discussion}

\subsection{Plasma electron temperatures}

The intensity ratio of the recorded $383.8 \mathrm{~nm}$ (Mg I) to $518.3 \mathrm{~nm}$ $\left(\mathrm{Mg}\right.$ I) spectra $\left(\mathrm{I}_{\mathrm{Mg}(3 \mathrm{~d} \rightarrow 3 \mathrm{p})} / \mathrm{I}_{\mathrm{Mg}(4 \mathrm{~s} \rightarrow 3 \mathrm{p})}\right)$ was used to determine plasma electron temperature $\left(T_{e}\right)$. The temperature results of experiments carried out under different conditions (Table 1) are presented in Fig. 1. It can be seen that the temperatures measured are in the range of $3300-7000 \mathrm{~K}$ for the unipolar case and for the bipolar case the range depends on the $\mathrm{I}^{+} / \mathrm{I}^{-}$current ratio and the phase current and the pulse duration time. For the S2 case the range is $3300-4500 \mathrm{~K}$ whereas for the S4 case the range is $3300-6800 \mathrm{~K}$. The low temperature range $(\sim 3300 \mathrm{~K})$ corresponds to the early stage discharges.

Fig. 1(a) shows plasma temperature profile for the unipolar current mode ( $\mathrm{S} 1$ ), where the temperature fluctuated around $3300 \mathrm{~K}$ within the first $10 \mathrm{~min}$, then the curve started to show a high number of closely-spaced temperature spikes ranging from 3300 to $4500 \mathrm{~K}$ with some of them reaching more than $6000 \mathrm{~K}$. These spikes corresponded to relatively strong discharges initiated from the sample surface-coating interface, the so-called B-type discharge [24], whereas the base line average is at $\sim 3500 \mathrm{~K}$. For the bipolar case S2 where $C_{R}=0.74$ the curve shown in Fig. 1(b) shows that the small spikes start to appear after $20 \mathrm{~min}$, however, these spikes are less frequent and cooler than that of the other samples. The temperature was less than $4500 \mathrm{~K}$ which may be attributed to the negative current phase as well as the timing of the pulses. Hence, it is believed that the strong B-type discharges were reduced or eliminated Fig. 1(b). For the case of S3, within the $30 \mathrm{~min}$ after the start of the process the temperature is in the range $3300-3500 \mathrm{~K}$. The average base temperature then started to increase to around $3500 \mathrm{~K}$ as can be seen from Fig. 1(c), and the maximum temperature was less than $6000 \mathrm{~K}$. For the bipolar case S4 where $C_{R}=1.0$ the curve shown in Fig. 1(d) shows that after 18 min from the start of the process, the spikes begin to appear with less density but the temperature reaches nearly $7000 \mathrm{~K}$ in some cases. The competition between the current phases from one side and the pulse durations from the other side can have a significant influence on the discharge mechanisms of the PEO process. Therefore, the $T_{e}$ profile depends strongly on the type of discharge and the current mode, and by using a bipolar current mode, the strong temperature spikes (due to B-type discharges) could be suppressed, or only appear at later times.

\subsection{Surface morphology and coating cross section}

The surface morphologies of three sets of PEO coatings, prepared under the process parameters listed in Table 1 are shown in the SEM micrographs in Fig. 2. There were a number of pancake features, micro-pores and microcracks distributed on the surfaces of all the PEO coatings. However, sample S1, which was fabricated with the unipolar current mode, contained relatively large holes, Fig. 2(a). The relatively large holes in the center of the pancake suggested that there had been strong discharges and such holes might penetrate deep in to the coating thickness. These strong discharges have been named as a B-type discharge in Ref. [24] to distinguish them from small and moderate discharges in the discharge model. Some microcracks appeared on the coating surface, which could be attributed to the thermal stresses during the progress of coating as a result of melting and solidification of the ceramic compounds such as magnesium oxide [33]. Samples S2 and S3, which were fabricated using the bipolar current mode, Fig. 2(b-c), showed a reduction in pore density and size. Such morphology was expected since both the number and strength of the strong B-type discharges were reduced by using the bipolar current mode, mainly due to the negative part of the pulses, as well as the off time of the pulses. Compared to sample S3, sample S2 showed an increase of small curly projections which added more irregularity to the surface morphology. The effect of the negative part of the pulse is critical, since it acts to dramatically reduce the effect of the strong B-type discharges, i.e. there will be a balance of the discharge effect. By allowing enough time for the oxide to cool down before other pulses were initiated, provides for longer sintering times and, therefore, a thick and hard coating with minimum porosity was produced.

Fig. 3 shows the SEM micrographs of cross-sections of the PEO coated $\mathrm{Mg}$ samples at two different current modes for treatment times of 45 min obtained using (a) back-scattered electron mode (BSE) and (b) secondary electron mode. Back-scattered electrons emerge from an appreciable depth (a few micrometers), and BSE images are better able to reveal features such as microporosity and microcracks which appear as a fine network of channels. All coatingsubstrate interfaces had a wavy-jagged appearance, which may be the result of dissolution of the substrate in the early stages of the treatment. The coating-substrate interface appears to follow the $\alpha-\mathrm{Mg}$ grain boundaries which are often decorated with the (Al, $\mathrm{Mg})_{4} \mathrm{Sr}$ and $\mathrm{Al}_{3} \mathrm{Mg}_{13} \mathrm{Sr}$ intermetallics [34]. The BSE images for S2 given in Fig. 3 show some evidence of intermetallics being retained at, or near, the coating/substrate interface. A similar interface appearance has been seen in a PEO-coated AM50 magnesium alloy [15]. This irregularity in the coating/substrate interface has a beneficial effect in improving the adhesion between the coating and substrate. The transverse section clearly shows that the coating is composed of 

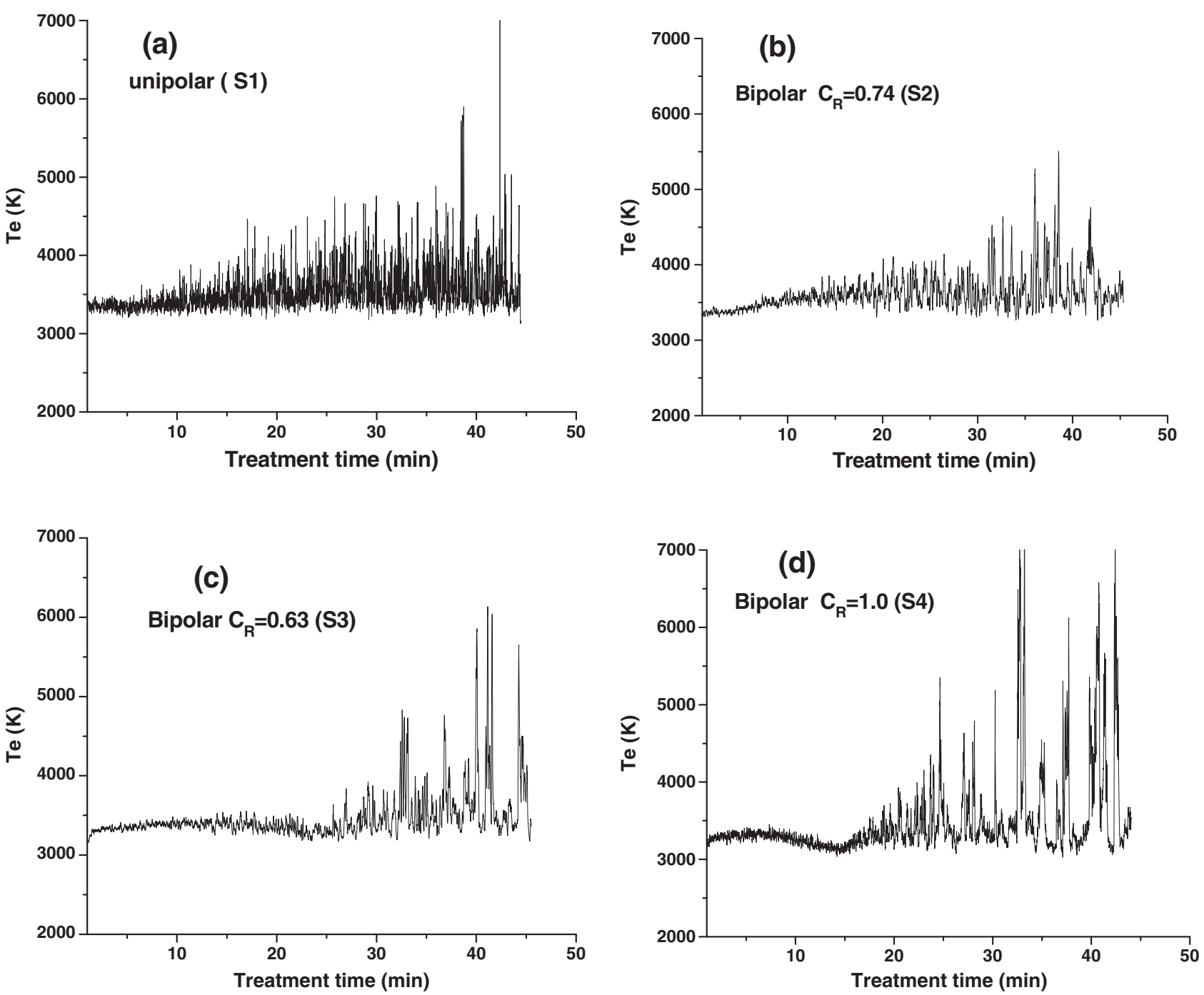

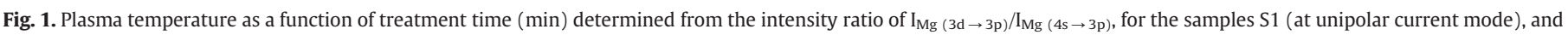
S2-S4 for the bipolar current mode.

two distinct layers, a porous outer layer on top of a denser inner layer. Also, there is evidence of a network of through-coating defects (micro cracks). Coating S1 at the unipolar current mode presented relatively porous microstructures, Fig. 3(S1). The coating appeared to have significant connected porosity, holes and other structure defects existed within the coating and near the coating/substrate interface, which would have a detrimental effect on the corrosion resistance, since localized electrochemical impedance spectroscopy on a PEO-coated MA8 magnesium alloy has shown that the corrosion process develops predominantly at the $\mathrm{Mg} /$ coating interface [35]. The coating thickness after the 45 min treatment time was about 40-60 $\mu \mathrm{m}$ at different locations of the cross section, and the loose layer accounts for about $30 \%$ or so of the total thickness. Such defects and porosity were likely caused by the strong B-type discharges. The high temperature
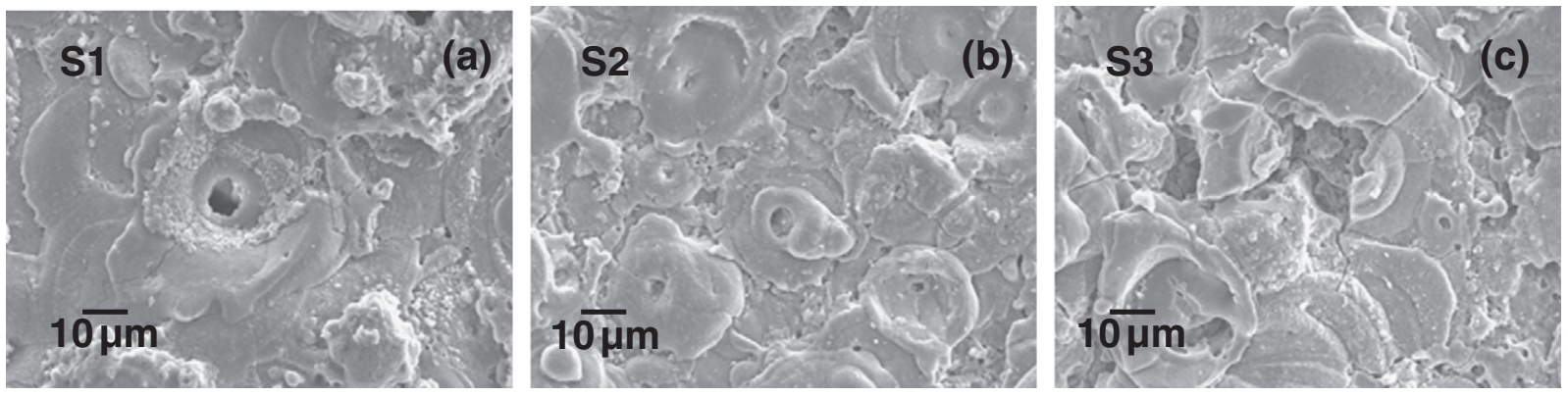

Fig. 2. SEM micrographs showing surface morphology of oxide coating on an Mg AJ62 alloy for: (a) unipolar and (b-c) bipolar current modes. 

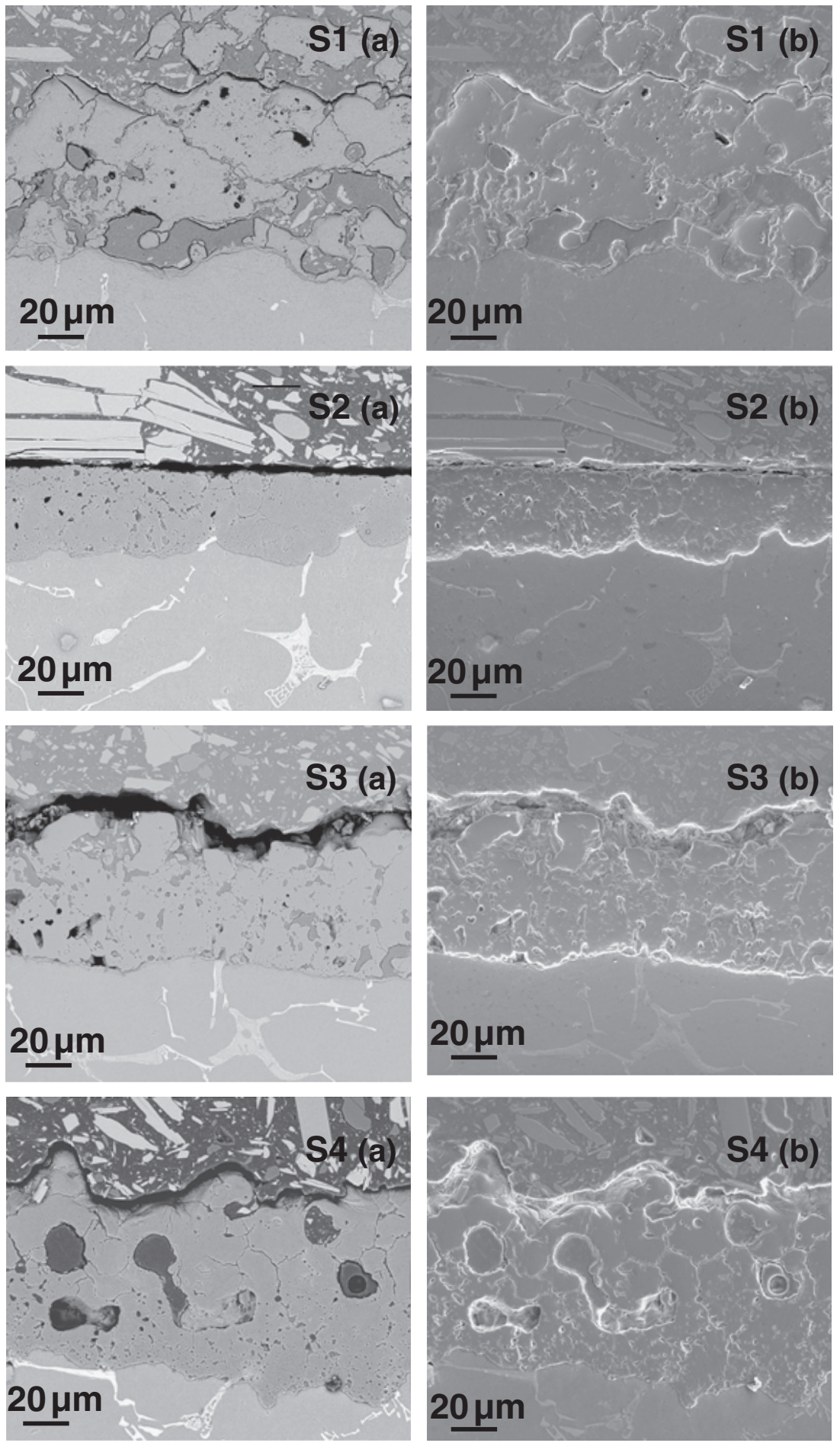

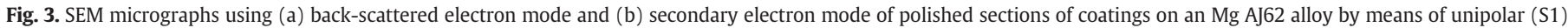
and bipolar (S2-S4) current modes.

generated by strong discharges melted the oxide and then some gasses were likely trapped in the interface layer between the substrate and the coating.

By using the bipolar current mode, there will be a balance of the discharge effects. The $\mathrm{T}_{\text {off }}$ duration should be long enough for the local molten oxide to be cool down before another pulse was initiated, while the $\mathrm{T}_{\text {on }}$ provided a long enough time for sintering and therefore a thick and hard coating with minimum porosity was produced. An inner layer was found underneath the relatively thin porous top layer in coatings S2 and S3, Fig. 3(S2-S3), obtained with the pulsed bipolar current mode, with smooth and minimum porosity and defects surface/coating interface. Fig. 3(S2) shows the oxide coating on samples S2 having thickness about 35-45 $\mu \mathrm{m}$ with very thin loose layer, while, the lower inner (dense) layer appeared to be smooth with minimum porosity. It is clear that beside the improvement of the surface morphology, Fig. 2(b), which results in formation of dense surface layer with less porosity and defects. The cathodic component of the bipolar current might suppress the strong discharges through draining out the electrical charges accumulated in the positive phase. The S2 sample was applied with the largest negative 
current, thus the strong discharges and plasma temperature spikes were reduced significantly, Fig. 1. As a result, the coating on S2 had a dense microstructure. However, the coating growth rate was slowed down. Compared to the sample S2, the sample S3 showed a thicker coating with relatively more porosity in the inner layer, Fig. 3(S3). The thickness of the oxide layer was in the range of $40-55 \mu \mathrm{m}$, and the ratio of outer loose layer thickness over the total coating thickness was less than 24\%. Compared to samples S2 and S3, sample S4 showed a thicker coating, about 55-80 $\mu \mathrm{m}$, with relatively more porosity in the dense layer with some microcracks, Fig. 3(S4).

XRD analysis of the PEO coatings indicated that all the PEO coatings were mainly composed of $\mathrm{MgAl}_{2} \mathrm{O}_{4}$ and $\mathrm{MgO}$. A transmission electron microscopy (TEM) study has also shown these phases existed in a PEO coating on AJ62 prepared using a unipolar mode [30]. Changing the current mode from unipolar to bipolar current mode did not alter the phases formed except for slight changes in the oxide peak intensity.

The melting point of the magnesia-alumina-spinel, $\mathrm{MgAl}_{2} \mathrm{O}_{4}$, is $2135^{\circ} \mathrm{C}$, and the presence of $\mathrm{MgAl}_{2} \mathrm{O}_{4}$ in the oxide layer is known to improve the corrosion resistance of $\mathrm{Mg}$ alloys. The phase composition and thickness of the coatings affect the corrosion resistance of the coatings. Ma et al. [36] showed that an enrichment of the $\mathrm{MgAl}_{2} \mathrm{O}_{4}$ spinel phase in the coating, together with a minimum amount of cubic $\mathrm{MgO}$, improves the corrosion resistance of the coating.

\subsection{Corrosion resistance of the coatings}

Fig. 4 shows the potentiodynamic polarization curves of the uncoated AJ62 Mg alloy (SO) and the PEO coated specimens using either unipolar or bipolar current modes (curves S1 and S2-S4 respectively). The corrosion potentials ( $\mathrm{E}_{\mathrm{corr}}$ ), corrosion current density $\left(\mathrm{I}_{\text {corr }}\right)$ and anodic/cathodic Tafel slopes $\beta_{\mathrm{a}}$ and $\beta_{\mathrm{c}}$ were derived from the test data. Based on the approximately linear polarization at the corrosion potential, the polarization resistance $\left(R_{p}\right)$ was determined [37] and is listed in Table 3. Coating S1 exhibits the lowest corrosion potential and polarization resistance but highest corrosion current density. The porous structure leads to the poorer corrosion resistance of the coating. Comparatively, coatings S2-S4, having a thick and relatively dense oxide layers, present higher corrosion potentials and polarization resistances but lower corrosion current densities than the coating S1.

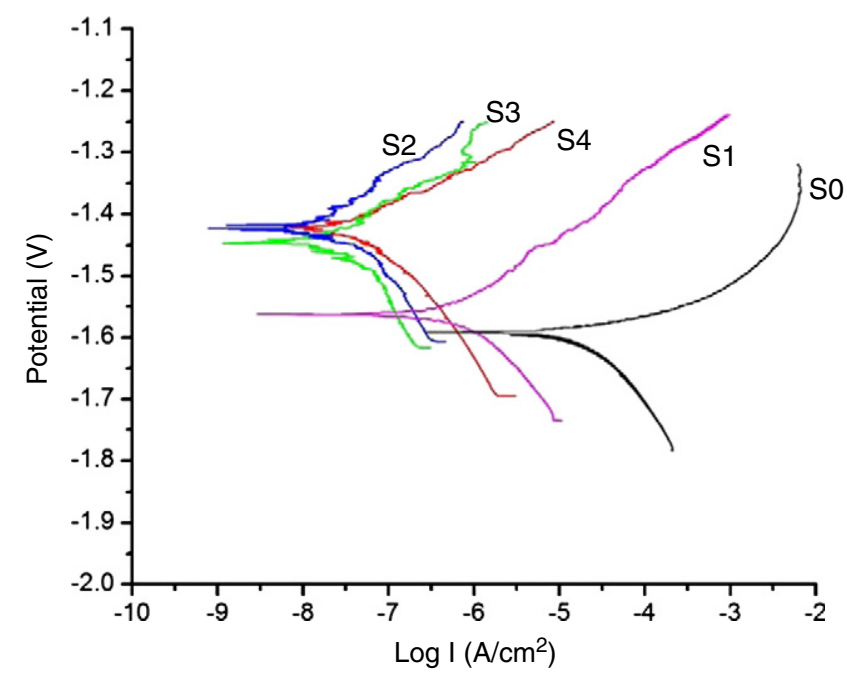

Fig. 4. Potentiodynamic polarization curves of the uncoated (SO) and coated samples using unipolar (S1) and bipolar (S2-S4) current modes.
Table 3

Potentiodynamic polarization corrosion test results in $3.5 \mathrm{wt} . \% \mathrm{NaCl}$ solution.

\begin{tabular}{llllll}
\hline & S0 & S1 & S2 & S3 & S4 \\
\hline $\mathrm{E}_{\text {corr }}(\mathrm{V})$ & -1.58 & -1.54 & -1.416 & -1.448 & -1.422 \\
$\mathrm{I}_{\text {corr }}\left(\mathrm{A} / \mathrm{cm}^{2}\right)$ & $2.24 \mathrm{E}-05$ & $5.39 \mathrm{E}-07$ & $1.20 \mathrm{E}-08$ & $1.50 \mathrm{E}-08$ & $4.30 \mathrm{E}-08$ \\
$\beta_{\mathrm{a}}(\mathrm{V})$ & 0.19 & 0.14 & 0.07 & 0.06 & 0.09 \\
$\beta_{\mathrm{c}}(\mathrm{V})$ & 0.05 & 0.08 & 0.06 & 0.13 & 0.10 \\
$\mathrm{R}_{\mathrm{p}}\left(\Omega \mathrm{cm}^{2}\right)$ & $7.11 \mathrm{E}+02$ & $4.10 \mathrm{E}+04$ & $1.24 \mathrm{E}+06$ & $1.19 \mathrm{E}+06$ & $4.72 \mathrm{E}+05$ \\
\hline
\end{tabular}

Since the bipolar current mode produces a thicker and denser coating, samples S2-S4 show a higher polarization resistance up to $1.24 \times 10^{6} \Omega$ for S2 case and lower corrosion current density than sample $\mathrm{S} 1$ coated by unipolar current mode, with a polarization resistance of $4.10 \times 10^{4} \Omega$ and higher corrosion current density. Although the sample S4 has a thicker coating than S2 and S3, its corrosion resistance is lower than those of S2 and S3. This is likely attributed to the micro cracks and relatively porous inner layer.

It is expected that a thicker coating gives rise to better corrosion resistance. However as the porosity level in the unipolar sample coating (S1) was quite high, it exhibited a lower corrosion potential compared to samples S2-S4 prepared using a bipolar current mode. Therefore, for better localized corrosion resistance the coating needs to be not only thicker, but also should be free from defects such as porosity $[33,38]$. The properties of the plasma discharges themselves in the bipolar current mode differ from those of the unipolar one. An increase of the $\mathrm{A}$ and $\mathrm{C}$ discharge types, and decrease of strong B discharges, moving over the surface being oxidized, have a significant effect on the coating properties, where a dense coating morphology could be achieved by adjusting the positive to negative current ratio and their timing to eliminate or reduce the strongest plasma discharges and thus the high temperature spikes [24].

Electrochemical impedance spectroscopy (EIS) measurements were performed at the open circuit corrosion potential on the PEO coatings in $3.5 \mathrm{wt} . \% \mathrm{NaCl}$ solution after $30 \mathrm{~min}$ of initial delay to stabilize the open-circuit potential (OCP). The EIS (Nyquist) diagrams are displayed in Fig. 5. The impedance data were analyzed using EC-Lab ${ }^{\circledR}$ software version 10.02 and best-fitted to the appropriate equivalent circuit model. In the fitting method, a combination of randomize followed by the most widely used optimization algorithm, Levenberg-Marquardt fitting, was used [39]. A randomization has been added before the fitting in order to help the algorithm to find the best couple of parameter values as close as possible to the real one (with minimum $X^{2}$ value). The goodness of the fit for this method is around $X^{2} \leq 1 . X^{2}$ used in this method is defined as follows [40]:

$X^{2}=\sum \frac{/ Z_{\text {meas }}(i)-Z_{\text {model }}\left(f_{i}, \text { param }\right) /^{2}}{\sigma_{i}^{2}}$

where $Z_{\text {meas }}(i)$ is the measured impedance at the $f_{i}$ frequency, $Z_{\text {model }}$ $\left(f_{i}\right.$, param $)$ is function of chosen model, $f$ is the frequency, param is the model parameters (ex: Rs, CPE1,...) and $\sigma_{i}$ is the standard deviation. The model chosen for the fitting was a commonly used model for PEO $[15,16,41]$ and other ceramic coatings $[42,43]$. The choice of the circuit was a balance between a reasonable fitting of the experimental values and a good description of the electrochemical system by keeping the number of circuit elements at a minimum. It is recognized that any electrode process is complex and usually consist of a many different sub-processes. The sub-processes include both mass transfer and charge transfer and can be in series or parallel with each other [43]. More complex equivalent circuits have been proposed by Ghasemi et al. [15] for PEO-coatings produced with $\mathrm{KOH} / \mathrm{Na}_{3} \mathrm{PO}_{4}$ and $\mathrm{KOH} /$ $\mathrm{NaAlO}_{2}$ electrolytes. In this model, a more general Constant Phase Element (CPE) was used instead of a capacitive element, which reflects the distributed surface reactivity, surface roughness, electrode porosity, and current and potential distributions associated with electrode 

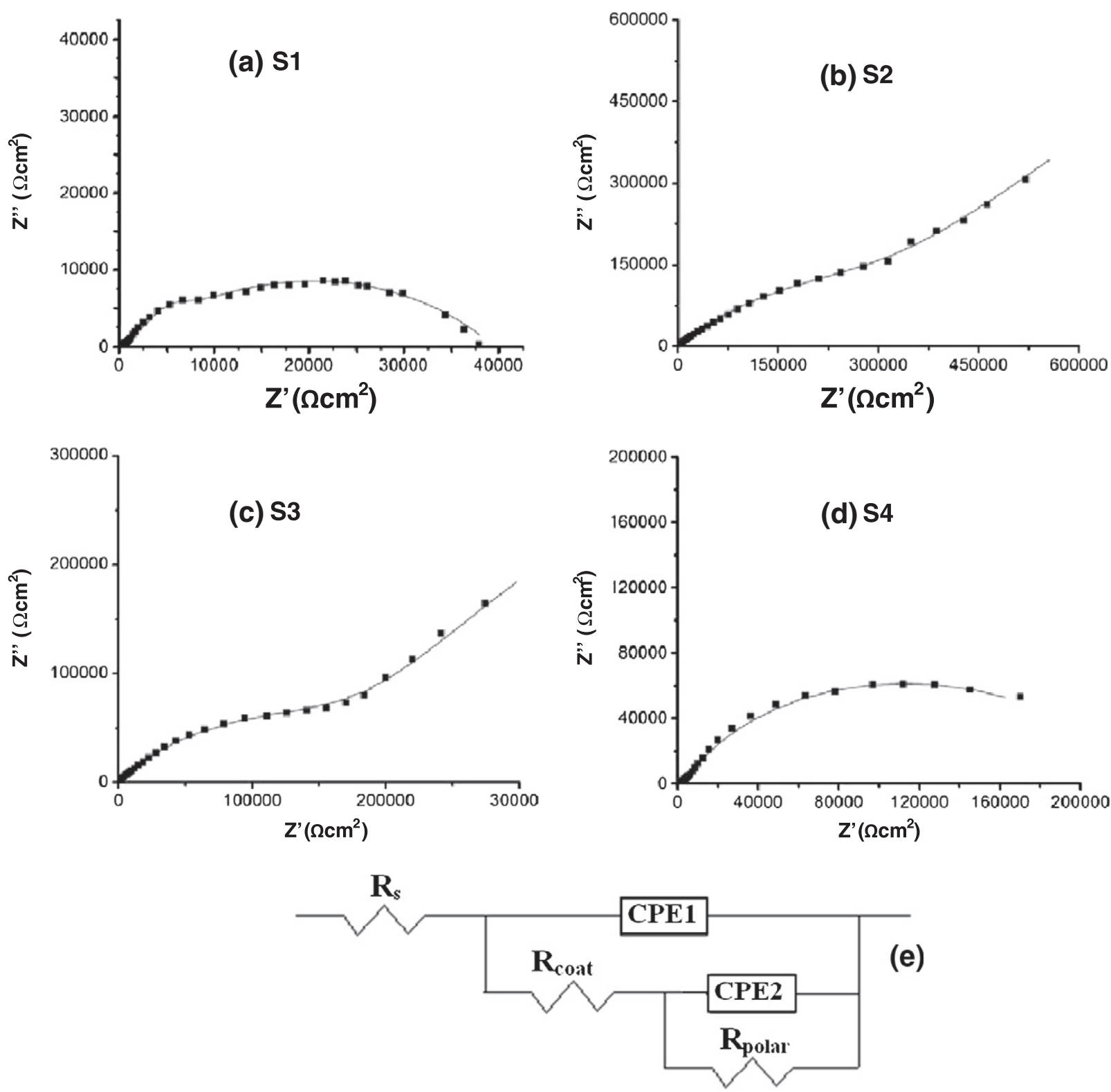

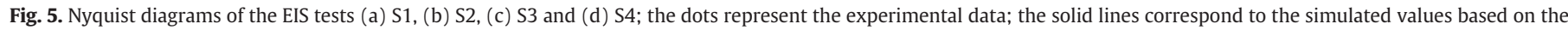
equivalent circuit model.

geometry [44]. The impedance of CPE is expressed by the following equation:

$\mathrm{Z}_{\mathrm{CPE}}=1 /\left[Q(j \omega)^{n}\right]$

where $Q$ is CPE constant, $j$ is the imaginary unit $(\sqrt{-1}), \omega$ is the angular frequency ( $1 \mathrm{rad} / \mathrm{s}$ ) of the sine wave being considered as $\omega=2 \pi f, f$ is the frequency in $\mathrm{Hz}$; the value of $n$ ranges between 0 and 1 . The value $0,0.5$ and 1 of $n$ imply the CPE of the circuit to be pure resistor, Warburg impedance and capacitor, respectively. A good fit was observed between the experimental data and the simulated values (Fig. 5). The circuit elements calculated from the fitting are summarized in Table 4.

The proposed equivalent circuit (Fig. 5(e)) consists of two time constants. $R_{S}$ is the solution (electrolyte) resistance. $R_{\text {coat }}$ is the coating resistance (virtual pore resistance [42]) which is parallel with a constant phase element CPE1 ( $C P E_{\text {coat }}$ in model of Ryu et al. [42]). CPE2 is the constant phase element for the double layer capacitance of the interface electrical double layer at or near the coating/substrate interface. $R_{\text {polar }}$ represents the polarization resistance which is the Faradic charge transfer resistance related to electrochemical reactions in the same coating/substrate interface region.

The $n$ values that are close to 0.5 for CPE1 indicate a diffusion (mass transfer) process of oxidized and reduced species. Diffusion components can be readily seen by the diffusion tails in the Nyquist diagrams for S2 and S3 coatings: see Fig. 5(b) and (c). The relatively

Table 4

Equivalent circuit data.

\begin{tabular}{lllll}
\hline & $\mathrm{S} 1$ & $\mathrm{~S} 2$ & $\mathrm{~S} 3$ & $\mathrm{~S} 4$ \\
\hline $\mathrm{R}_{\mathrm{s}}\left(\Omega \mathrm{cm}^{2}\right)$ & 20 & 25 & 27 & 28 \\
$\mathrm{CPE} 1-\mathrm{Q}\left(\mu \mathrm{F} / \mathrm{cm}^{2} \mathrm{~s}^{1-\mathrm{n}}\right)$ & 5.11 & 0.59 & 0.69 & 0.22 \\
$\mathrm{CPE} 1-\mathrm{n}$ & 0.5378 & 0.5296 & 0.5631 & 0.5256 \\
$\mathrm{R}_{\text {coat }}\left(\Omega \mathrm{cm}^{2}\right)$ & $3.91 \mathrm{E}+04$ & $4.7 \mathrm{E}+05$ & $2.4 \mathrm{E}+05$ & $6.3 \mathrm{E}+03$ \\
$\mathrm{CPE} 2-\mathrm{Q}\left(\mu \mathrm{F} / \mathrm{cm}^{2} \mathrm{~s}^{1-\mathrm{n}}\right)$ & 0.076 & 2.97 & 4.64 & 1.01 \\
$\mathrm{CPE} 2-\mathrm{n}$ & 0.9195 & 0.5664 & 0.7026 & 0.7752 \\
$\mathrm{R}_{\text {polar }}\left(\Omega \mathrm{cm}^{2}\right)$ & $3.19 \mathrm{E}+02$ & $2.33 \mathrm{E}+06$ & $1.56 \mathrm{E}+06$ & $2.29 \mathrm{E}+05$ \\
$\mathrm{R}_{\text {total }}\left(\Omega \mathrm{cm}^{2}\right)$ & $3.94 \mathrm{E}+04$ & $2.80 \mathrm{E}+06$ & $1.80 \mathrm{E}+06$ & $2.35 \mathrm{E}+05$ \\
\hline
\end{tabular}


high coating resistance $\left(R_{\text {coat }}\right)$ and lower coating capacitances (CPE1) of bipolar samples S2 and S3 compared to the unipolar sample S1, reflect the smaller amount of ionic conducting pathways which could be pores or microcracks in the bipolar coatings. The very high $R_{\text {polar }}$ resistance values for samples S2 and S3 compared to S1 and S4 indicate that the microstructure at the coating/substrate interface in these two samples (S2 and S3) acts as a much better barrier to penetration of the aggressive electrolyte to the metal substrate. It is interesting to note that the values obtained by EIS for the total resistances of the coating $R_{\text {coat }}+R_{\text {polar }}$ (see Table 4 ) follow the same order, $\mathrm{S} 2>\mathrm{S} 3>\mathrm{S} 4>\mathrm{S} 1$, as for Rp in the potentiodynamic polarization tests.

\section{Discussion}

The influence of current mode and pulse duration on the coating morphology, thickness and corrosion resistance was significant. The use of the unipolar current mode results in the production of significant porosity and other structural defects, e.g. microcracks, which degrade the coatings, corrosion resistance. The application of a bipolar mode with a cathodic component, changes the sample surface morphology, resulting in the formation of a thicker and denser inner layer with fewer defects, and a thin, porous outer layer. The properties of the plasma discharges themselves in the bipolar current mode differ from those of the unipolar one. An increase of the $\mathrm{A}$ and $\mathrm{C}$ discharge types, and decrease of strong $\mathrm{B}$ discharges $[20,24]$, moving over the surface being oxidized, have a significant effect on the coating properties. The cathodic component not only helps to eliminate, or at least reduces, the strong B-type discharges during the subsequent anodic period, but also directly affects the coating growth process. By reducing or eliminating the strong B-type discharges, and hence reducing the high temperature spikes, the average plasma temperature was to some extent also decreased. However, these reduced temperatures are still sufficient to allow reaction between the magnesium and aluminum oxides leading to the formation of a surface layer with the magnesium aluminate spinel structure with good anticorrosion properties. This confirms the importance of current regimes together with the pulse timing in providing appropriate thermodynamic conditions for the formation of corrosion resistant PEO layers on magnesium alloys.

\section{Conclusions}

1- Two different current modes during the PEO processes in sodium aluminates electrolytes were used to produce oxide coatings on an Aj62 alloy. Both modes successfully improve the corrosion resistance as compared to that of the uncoated alloy. However, the coating made using the bipolar current mode is more beneficial in improving the corrosion resistance of the PEO coating than that of the unipolar current mode.

2- The plasma temperatures were characterized by means of OES, and it was found that the plasma temperature vs. process time relationship was different under different current operating modes. The plasma temperature spikes were believed to be caused by the strongest plasma discharges initiated at the interface between the oxide coating and substrate. Controlling or reducing the strong discharges had significant effects on the plasma temperature profiles and the quality and characteristics of the coating layers. Compared to the unipolar current process, the application of pulsed bipolar current resulted in reducing the high spikes on temperature profiles and the average plasma temperature. This work showed that by appropriately controlling the ratio of the positive to negative pulse currents as well as their timing, the very strong plasma discharges and the resulted high temperature spikes could be eliminated and hence the quality of the coatings was considerably improved.

3- The results showed that the anions in the electrolyte solution directly contributed to the coating formation process. Apart from $\mathrm{MgO}$ which is a common phase in the coatings, a specific phase, $\mathrm{MgAl}_{2} \mathrm{O}_{4}$, resulted from the aluminate electrolyte.
4- The electrochemical corrosion experiments show that the corrosion resistance of the AJ62 alloy was considerably increased by PEO oxide coating. The corrosion resistance of the PEO specimens was mainly determined by the structure of the oxide at, or near, the coating/substrate interface. Samples coated using the bipolar current mode exhibit higher $R_{\text {polar }}$-values indicating the presence of a good barrier to the penetration of the aggressive electrolyte to the metal surface.

\section{Acknowledgments}

This research was supported by Ontario Centres of Excellence (OCE) and the Natural Sciences and Engineering Research Council of Canada (NSERC). Dr. Y Xia was a Senior Visiting Scholar at the University of Windsor during this research project.

\section{References}

[1] Magnesium Die Casting Handbook (201), NADCA, Illinois, 1998.

[2] M.K. Kulekei, Int. J. Adv. Manuf. Technol. 39 (2008) 851

[3] M.O. Pekguleryuz, A.A. Kaya, in: K.U. Kainer (Ed.), Magnesium Proc. 6th. Int. Conference Magnesium Alloys and Their Applications, Wiley-VCH, Weinheim, Germany, 2004, p. 74

[4] R. Osborne, G. Cole, M.C. Bruce, D. Penrod, Proc. 57th Annual World Magnesium Conference, Vancouver, Canada, 2000 May, p. 1.

[5] L.H. Hihara, R.M. Latanision, Inter. Mat. Rev. 39 (6) (1994) 245.

[6] C. Gu, J. Lian, J. He, Z. Jiang, Q. Jiang, Surf. Coat. Technol. 200 (2006) 5413.

[7] H. Altun, S. Sen, Surf. Coat. Technol. 197 (2005) 193.

[8] J.E. Gray, B. Luan, J. Alloy and Comp. 336 (2002) 88.

[9] S.V. Gnedenkov, O.A. Khrisanfova, A.G. Zavidnaya, S.L. Sinebryukhov, V.S. Egorkin, M.V. Nistratova, A. Yerokhin, A. Matthews, Surf, Coat. Technol. 204 (2010) 2316.

[10] Y. Ma, X. Nie, D.O. Northwood, H. Hu, Thin Solid Films 469-470 (2004) 472.

[11] A. Ghasemi, V.S. Raja, C. Blawert, W. Dietzel, K.U. Kainer, Surf. Coat. Technol. 202 (2008) 3513.

[12] X. Nie, L. Wang, E. Konca, A.T. Alpas, Surf. Coat. Technol. 188-189 (2004) 207.

[13] C. Blawert, W. Dietzel, E. Ghali, G. Song, Advanced Engineering Materials 8 (2006) 511.

[14] A.L. Yerokhin, X. Nie, A. Leyland, A. Matthews, J. Dowey S, Surf. Coat. Technol. 122 (1999) 73.

[15] A. Ghasemi, V.S. Raja, C. Blawert, W. Dietzel, K.U. Kainer, Surf. Coat. Technol. 204 (2010) 1469 .

[16] Y.G. Ko, S. Namgung, D.H. Shin, Surf. Coat. Technol. 205 (2010) 2525

[17] H. Luo, Q. Cai, B. Wei, B. Yu, D. Li, J. He, Z. Liu, J. Alloys and Compounds 464 (1-2) (2008) 537.

[18] J. Liang, P.B. Srinivasan, C. Blawert, M. Stormer, W. Dietzel, Electrochimica Acta 54 (14) (2009) 3842

[19] E. Cakmat, K.C. Tekin, U. Malsyooglu, S. Shrestha, Surf. Coat. Technol. 204 (2010) 1305.

[20] R.O. Hussein, X. Nie, D.O. Northwood, Surf. Coat. Technol. 205 (2010) 1659.

[21] A.L. Yerokhin, A. Shatrov, V. Samsonov, P. Shashkov, A. Pilkington, A. Leyland, A. Mathews, Surf. Coat. Technol. 199 (2005) 150.

[22] J.A. Curran, W.T. Clyne, Surf. Coat. Technol. 199 (2005) 168.

[23] R. Arabal, E. Matykina, T. Hashimoto, P. Skeldon, G. Thompson, E Surf. Coat. Technol. 203 (2009) 2207

[24] R.O. Hussein, X. Nie, D.O. Northwood, A.L. Yerokhin, A. Matthews, J. Phys. D: Appl. Phys. 43 (2010) 105203.

[25] R.O. Hussein, X. Nie, D.O. Northwood, J. Vac. Sci. Technol. A 28 (4) (2010) 766.

[26] A.L. Yerokhin, L.O. Snizhko, N.L. Gurevina, A. Leyland, A. Pilkington, A. Matthews, J. Phys. D: Appl. Phys. 36 (2003) 2110.

[27] H.R. Griem, Plasma Spectroscopy, McGraw-Hill, Cambridge, 1964.

[28] M. Kunst, A. Fischersworring-Bunk, G. L'Esperance, P. Plamondon, U. Glatzel, Mat. Sci. and Eng. A 510-511 (2009) 387.

[29] P. Zhang, X. Nie, D.O. Northwood, Surf. Coat. Technol. 203 (2009) 3271.

[30] P. Zhang, X. Nie, H. Hu, Y. Liu, Surf. Coat. Technol. 205 (2010) 1508.

[31] R.O. Hussein, P. Zhang, D.O. Northwood, X. Nie, Australasion Corrosion Association Inc (ISSN 1442-0139), Paper 037, 2010, p. 1.

[32] Sansonetti J E and Martin W C 2005 J. Phys. Chem. Ref. Data, 34 [4] 1559.

[33] P.B. Srinivasan, J. Liang, C. Blawert, M. Stormer, W. Dietzel, App. Surf. Sci. 255 (2009) 4212.

[34] A. Kielbus, Archives of Materials Science and Engineering 28 (6) (2007) 345.

[35] S.L. Sinebryukhov, A.S. Gnedenkov, D.V. Mashtalyar, S.V. Gendenkov, Surf. Coat. Technol. 205 (2010) 1697.

[36] Y. Ma, X. Nie, D.O. Northwood, H. Hu, Thin Solid Films 494 (2006) 296

[37] R.W. Revie, Uhlig's Corrosion Handbook, 2nd ed. John Wiley \& Sons, New York, 2000.

[38] H.S. Ryu, S.-H. Hong J. Electrochem. Soc. 157 (4) (2010) C131.

[39] J. Nocedal, S.J. Wright, Numerical Optimization, Springer, New York, 1999.

[40] EC-Lab® Software User's Manual, 2010, http://www.bio-logic.info/

[41] D.Y. Hwang, Y.M. Kim, D.H. Shin, Material Transaction 50 (3) (2009) 671.

[42] H.S. Ryu, J. Ryu, D. Park, S.-H. Hong, J. Electrochem. Soc. 158 (2) (2011) C23.

[43] Y. Zhang, C. Yan, F. Wang, W. Li, Corrosion Sci. 47 (2005) 2816.

[44] J.B. Jorcin, M.E. Orazem, N. Pébère, B. Tribollet, Electrochim. Acta 51 (2006) 1473. 